\title{
A Formação dos Profissionais do Setor de Modelagem do Vestuário da Região do Vale do Itajaí-SC
}

por Icléia Silveira; Lucas da Rosa; Maria Izabel Costa, Luciana Dornbusch Lopes

RESUMO

Este artigo apresenta os resultados de uma pesquisa quantitativa, que teve como objetivo identificar a formação dos profissionais do setor de modelagem que atuam nas empresas do vestuário da Região do Vale do Itajaí de Santa Catarina. A identificação das empresas para a pesquisa foi obtida através do Guia Web SC (total: 932 empresas). A análise dos dados comprovam que 53\% dos profissionais do setor de modelagem possuem curso de nível técnico, 34\% são formados pelas universidades e $13 \%$ são antigas costureiras que aprenderam 0 oficio no trabalho do dia a dia.

Palavras-chave modelagem; vestuário; conhecimento; formação 


\section{A Formação dos Profissionais do Setor de Modelagem do Vestuário da Região do Vale do Itajaí-SC}

\section{Introdução}

As universidades e as instituições de ensino de nível técnico são importantes parceiras para que as empresas do vestuário saiam da visão de produção e de processos tradicionais, voltando-se a pesquisas, processos de design, novas tecnologias e inovação. Neste contexto, a formação profissional do modelista do vestuário influencia diretamente na qualidade do produto, pois é ele, que idealiza os modelos criados pelos designers de moda.

Essa pesquisa aborda os conhecimentos necessários à formação profissional do modelista, suas funções básicas e habilidades necessárias à qualidade da modelagem. Neste sentido, se propõe identificar a formação e o perfil dos profissionais que atuam nas empresas do vestuário da Região do Vale do Itajaí, Santa Catarina, no setor de modelagem.

A etapa da modelagem faz parte do desenvolvimento do produto de moda do vestuário, exigindo o trabalho de profissionais capacitados, com conhecimentos de todas as etapas deste processo, desde pesquisas de mercado, tendências de moda, processos criativos, produtivos e de comercialização. Isto reflete na qualidade dos produtos, fator fundamental para o sucesso das vendas, e neste processo, a modelagem das peças do vestuário ganha ainda mais valor se aliada ao desejo do consumidor em adquirir produtos que tenham, ao mesmo tempo, perfeito caimento sobre as linhas estruturais do corpo humano, além dos padrões estéticos e tendências de moda, envolvidos no processo criativo.

Por isso, o modelista deve buscar conhecimentos mais específicos da ergonomia física, aqueles que se ocupam das características humanas como a antropometria, fisiologia e biomecânica, relacionadas com a forma e os movimentos do corpo humano, além das atividades realizadas pelo indivíduo e a função do vestuário, a fim de adaptar o produto ao usuário.

São também, indispensáveis, os conhecimentos sobre os tecidos, pois dão a noção de como vão assumir a forma ou o estilo do modelo. Quando não é usado o tecido adequado ao modelo, por suas características técnicas ou sua estrutura, o visual idealizado fica comprometido, tornando inviável a produção. Não se trata só de uma questão estética, mas também, de peso e caimento do vestuário sobre o corpo humano.

0 conhecimento das máquinas e equipamentos, bem como das etapas da montagem do vestuário, influenciam nas competências do modelista, porque permitem a compreensão sobre a viabilidade técnica do produto, dando mais segurança a este profissional e mais qualidade ao traçado da modelagem.

\section{A Modelagem Industrial}

No processo de desenvolvimento do produto do vestuário, a etapa de grande responsabilidade pela adaptação do produto ao usuário é a modelagem industrial. 


\section{A Formação dos Profissionais do Setor de Modelagem do Vestuário da Região do Vale do Itajaí-SC}

A realização dos procedimentos técnicos, parte do princípio da representação do corpo humano, por meio de um plano. Esse se dá pelo posicionamento das linhas verticais e horizontais em ângulos, que se relacionam com o plano de equilíbrio do corpo, simetria, alturas, comprimentos e relações de proporções entre as partes.

A modelagem plana industrial pode ser realizada manualmente e por meio de sistemas computadorizados, utilizando os princípios da geometria para traçar os diagramas bidimensionais, as formas do modelo e os moldes, sempre observando as formas do corpo do usuário.

A modelagem consiste numa atividade voltada à planificação da roupa, a fim de viabilizar sua produção em escala industrial. Trata-se da técnica responsável pela interpretação do modelo do vestuário sobre o diagrama básico do corpo humano, que reproduzem suas formas, representando as partes do vestuário, que são os moldes. Os moldes, uma vez colocados sobre o tecido, cortados e unidas por costuras, resultarão nas peças do vestuário (SILVEIRA, 2003).

A interpretação do modelo é executada a partir de uma análise do desenho técnico e das demais especificações do produto. 0 processo de elaboração da modelagem consiste numa fase que envolve os estudos dos fatores ergonômicos, da antropometria e o conhecimento do público alvo. Assim, o processo de modelagem industrial determina por meio de suas características, as formas, volumes, caimento e conforto do vestuário.

A modelagem é trabalhada com padrões determinados, sendo necessário, portanto, utilizar-se de tabelas de medidas que se assemelham ao padrão médio do corpo, dentro de uma numeração pré-estabelecida. 0 padrão médio brasileiro para 0 corpo feminino é o manequim $n^{0} 42$, enquanto que para o corpo masculino é $0 n^{0} 3$, sendo ambos correspondentes ao tamanho médio. Para executar a modelagem do protótipo, adotam-se estes dois tamanhos principalmente pela facilidade de poder testar em pessoas que possuam as medidas aproximadas, favorecendo posteriormente a graduação dos moldes.

Os moldes industriais exigem cuidados, como as marcações das larguras das costuras, indicações nos moldes das posições dos bolsos, botões, casas, pences, zíperes, etc., indicação da direção do fio do tecido e outros detalhes necessários para a realização do corte.

No caso da indústria do vestuário que já tenha implantado o sistema CAD (Desenho Assistido por Computador) a modelagem poderá ser realizada diretamente no computador através do sistema. 0 primeiro passo é criar as bases e sobre elas, trabalhar os modelos desejados. Pode-se, também, transferir moldes prontos para o computador, através de softwares e equipamentos específicos.

A partir do momento que a modelagem estiver pronta, cria-se um arquivo para salvá-la. Assim, quando precisar criar um novo modelo, pode-se fazer uso dos traçados básicos já existentes e arquivados, bastando apenas, importá-los para a tela, abri-los num arquivo novo e manipulá-los para fazer as devidas alterações até se chegar ao 


\section{A Formação dos Profissionais do Setor de Modelagem do Vestuário da Região do Vale do Itajaí-SC}

modelo desejado. Depois de aprovado o protótipo é feita a graduação (ampliação e redução dos moldes) e o encaixe (posicionamento dos moldes de vários tamanhos a fim de obter o melhor aproveitamento do tecido, de maneira manual ou com o uso do sistema informatizado). Para executar a modelagem do vestuário, necessita-se de um profissional altamente qualificado, que é valorizado pelas empresas, pela responsabilidade da função. Descrevem-se, abaixo, as características deste profissional.

\section{Modelista Industrial}

0 modelista é o profissional que dentro da indústria do vestuário, interpreta os modelos criados pelo designer de moda e os transforma em objeto concreto. A partir destes modelos (peça piloto), serão confeccionados outros, de acordo com os pedidos.

É indispensável para todos os profissionais deste ramo, estar atualizado com a moda, os lançamentos, as tendências, os novos materiais e processos tecnológicos, pois estes conhecimentos darão ao profissional a possibilidade de intervir na qualidade dos processos industriais.

Como já destacado, o trabalho do modelista vai refletir na produção, pois o sucesso de uma coleção depende dos seus conhecimentos, experiências e habilidades. Destaca-se as unidades de conhecimentos necessárias à formação dos modelistas, no Quadro 1.

\section{UNIDADES DE CONHECIMENTO PARA A FORMAÇÃO DO MODELISTA}

Interpretar a representação gráfica de modelos do vestuário proposto pelo setor de criação. Entender a linguagem de moda para se relacionar com a equipe de criação;

Identificar os tecidos e os aviamentos, suas aplicações, incluindo as propriedades físicas e mecânicas dos mesmos, como caimento e maquinário apropriado para a sua confecção;

Aplicar nos diagramas básicos do corpo humano os fatores técnicos e funcionais - qualidades ergonômicas e antropométricas, com vistas à usabilidade do produto;

Desenvolver a modelagem do vestuário com técnicas bidimensionais ou tridimensionais. Executar a graduação dos moldes;

Saber operar com sistemas computadorizados - Ferramentas CAD/CAM;

Conhecer todas as etapas da produção do vestuário;

Complementar a base de dados da Ficha Técnica do Produto, quanto à definição dos materiais, fornecedores, consumo, detalhes de qualidade e de montagem;

Identificar tipos de máquinas de costura e aparelhos;

Ser um prototipista das peças que modela - saber cortar e costurar;

Saber trabalhar e compartilhar conhecimentos em equipe, e ter autonomia de criação e solução de problemas.

Quadro 1. Conhecimentos para a Formação do Modelista 


\section{A Formação dos Profissionais do Setor de Modelagem do Vestuário da Região do Vale do Itajaí-SC}

Diante do que foi descrito, sobre os conhecimentos necessários à formação do modelista, fica evidente, que este profissional, deve comunicar-se com os demais setores da empresa, para tomar conhecimento de todos os processos, que envolve o desenvolvimento do produto.

É importante para a empresa que os setores de criação, modelagem, corte e confecções realizem entre si a disseminação dos conhecimentos usados nos processos produtivos. As experiências de trabalho e habilidades dos profissionais destes setores, sendo compartilhadas para soluções de problemas, levam necessariamente à criação de novos conhecimentos, que serão aplicados nos processos e nos produtos. Destacam-se na sequência os procedimentos metodológicos aplicados na pesquisa de campo.

\section{Procedimentos Metodológicos}

Os procedimentos metodológicos da pesquisa alicerçam-se na proposta do método quantitativo, com abordagem exploratória e descritiva, realizada através de uma pesquisa de campo.

A amostra da Pesquisa - No banco de dados da CIESC (Centro Das Indústrias Do Vestuário de Estado de Santa Catarina) obteve-se a identificação de 488 empresas do vestuário, do segmento de roupas feminina, masculina e infantil, separadas por regiões, municípios, ramo de atividades, número de funcionários e por porte: 288 microempresas, 143 pequenas empresas, 47 médias empresas e 10 grandes empresas. A limitação da pesquisa considerou às características da amostra, que envolveu somente as empresas do vestuário da Região do vale do itajaí e neste contexto, o setor de modelagem. Optou-se em enviar o questioário a todas as 488 empresas desta região, na tentativa de obter a maior participação possível. Responderam ao questionário 248 empresas.

Os procedimentos metodológicos apresentou as seguintes etapas:

a. As empresas foram relacionadas pelo endereço eletrônico, mantendo-se a divisão por porte;

b. A pesquisa de campo foi iniciada no mês de maio de 2010, com o envio das correspondências (documento com o questionário) por e-mail para cada empresa;

c. As respostas foram sendo organizadas e os e-mails respondidos arquivados;

d. Todas as semanas, os e-mails não respondidos eram reenviados, retornando-se ao processo anterior;

e. Após se esgotarem as possibilidades da realização da pesquisa via e-mail, a mesma passou a ser realizada por telefone;

f. A pesquisa de campo foi concluída em 30 de novembro de 2011;

g. Os dados obtidos foram organizados, processados, tabulados e analisados. 


\section{A Formação dos Profissionais do Setor de Modelagem do Vestuário da Região do Vale do Itajaí-SC}

\section{Contexto da Região do vale do Itajaí}

É importante evidenciar que o Estado de Santa Catarina é o segundo polo produtor têxtil e de vestuário do Brasil. Neste contexto, destaca-se o complexo têxtil/vestuário do Vale do Itajaí, que movimenta a economia desta região num processo dinâmico que iniciou com a tradição industrial do vestuário, trazida pelos imigrantes alemães que se fixaram nesta região.

0 setor têxtil vestuarista catarinense é grande gerador de empregos e tem como característica o predomínio de empresas de micro e pequeno porte, ao lado de grandes empresas líderes.

As primeiras unidades fabris têxteis em Santa Catarina localizaram-se no Vale do Itajaí, em fins do século XIX, criadas por iniciativas de artesões e operários de origem que emigraram, em grande quantidade da Alemanha, em consequência das crises econômicas e transformações políticas institucionais. Estes imigrantes eram de origem urbana e com formação operária, comercial, industrial e intelectual, o que contribuiu para a criação das empresas nesta região (BOSSLE, 1988).

Neste contexto histórico, foi-se multiplicando o surgimento de empresas têxteis, nas localidades de Blumenau, Brusque, Gaspar, Indaial, Timbó e Jaraguá do Sul, cuja trajetória de crescimento conduziu para a constituição do maior aglomerado industrial têxtil-vestuário do sul do país. Sendo que, atrelado a este movimento, na região do Vale do Itajaí criaram-se inúmeras pequenas e médias empresas que se beneficiavam das sinergias existentes colocadas em termos de um contingente de trabalhadores com conhecimentos têxteis, baixo volume de capital requerido à entrada na indústria para pequenos empreendimentos, tecnologia conhecida e difundida, etc.

Além disso, a região é favorecida pela existência de dois portos para transporte de produtos, o Porto de São Francisco do Sul que fica localizado próximo à região do Vale do Itajaí, movimentando produtos como granéis, madeiras, papel, têxteis, etc e o Porto de Itajaí que se localiza na região do Vale do Itajaí, movimentando também, produtos têxteis, contêineres frigoríficos, madeira, máquinas, motores etc (LINS, 2003).

As empresas produtivas desta região caracterizam-se quase que exclusivamente do ramo têxtil e vestuário, com fornecimento externo da principal matéria prima - 0 algodão, da uma parte dos equipamentos, das fibras e tecidos sintéticos e da maior parte dos insumos químicos. Formam o conjunto dos segmentos mais específicos da cadeia têxtil-vestuário, à base de algodão, ou seja, fiação, tecelagem, tinturaria, acabamento e confecção.

Os principais produtos são artigos de vestuário (camisetas de malha, agasalhos de moletom, pijamas, camisas pólo, bermudas, blusas, linha íntima masculina e feminina etc.), tecidos planos e de malha, artigos felpudos (toalhas e roupões), artigos de cama e mesa (lençóis, travesseiros, colchas, edredons, toalhas de mesa, cortinados etc.), fios (linhas de algodão para crochê e bordado, cadarços etc.) produtos têxteis hospitalares (compressas e ataduras de gaze, fraldas de tecido, esparadrapo etc.), fitas elásticas e etiquetas tecidas. A renda per capita média desta região é quase 0 dobro da média nacional (IEMI, 2007). 


\section{A Formação dos Profissionais do Setor de Modelagem do Vestuário da Região do Vale do Itajaí-SC}

\section{Resultado e Análise da Pesquisa}

A primeira pergunta do questionário (A empresa possui modelista no seu quadro de profissionais) teve como objetivo identificar o percentual de empresas que possuem este profissional em seus quadros de funcionários.

Destaca-se, através da análise dos dados referente à Região do Vale do Itajaí, a grande inserção dos profissionais da modelagem atuando nas empresas do vestuário. Este fato vem de encontra a valorização do trabalho deste profissional por parte das empresas. Estas sabem que a qualidade do produto depende da qualidade da modelagem, e esta por sua vez da formação acadêmica do modelista. A capacitação e inserção destes profissionais no mercado de trabalho estão sendo influenciadas pelas instituições de ensino de moda, em grande número no estado, e também pela qualidade dos cursos de nível técnico oferecidos principalmente pelo SENAI (Serviço Nacional de Aprendizagem Industrial) e SENAC (Serviço Nacional do Comércio).

A segunda pergunta do questionário investiga a origem da formação dos modelistas que atuam nas empresas do vestuário da Região do Vale do Itajaí.

Observa-se no Gráfico 01, que é pequena a representação (13\%) das antigas costureiras da empresa que com o passar do tempo adquiriram conhecimentos e habilidades práticas do saber fazer e hoje são responsáveis pela modelagem do vestuário. Nesta região a presença dos profissionais com curso técnico $53 \%$ representam a valorização e segurança por parte das empresas na contratação destes profissionais, que dominam conhecimentos práticos e vivenciam seus estágios no chão de fabrica. A presença de modelistas formados em curso superior vem se destacando, representam $34 \%$ do total. Nesta região o curso de moda mais antigo data de 1997 (Blumenau), os demais foram criados recentemente, porém os cursos técnicos são muito atuantes e especializados na produção do vestuário.

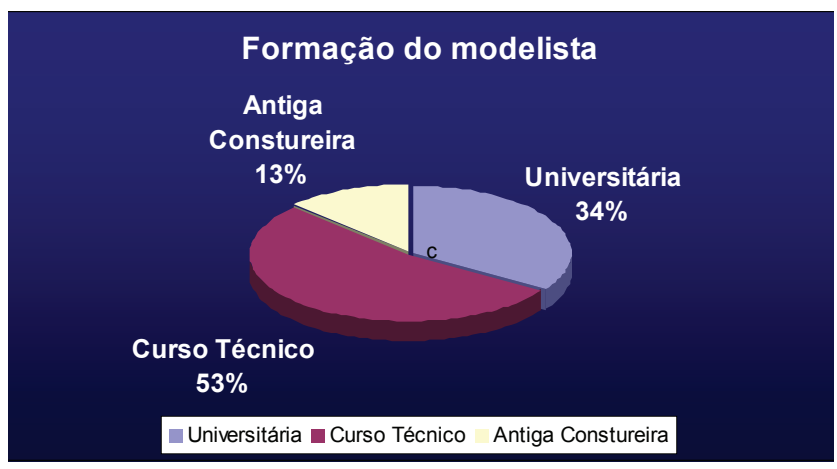

Gráfico 1. Formação do Modelista da Região do Vale do Itajaí Fonte: Dados primários, 2011

A região do vale do Itajaí, apesar de possuir os maiores números de empresas do vestuário em Santa Catarina, tem mais profissionais formados em cursos técnicos 


\section{A Formação dos Profissionais do Setor de Modelagem do Vestuário da Região do Vale do Itajaí-SC}

do que nos cursos superiores de moda. Acredita-se que a contratação de profissionais de nível superior ainda é vista com um pouco de desconfiança. Os empresários receosos apostam mais nos profissionais formados nos cursos técnicos. Claro que não é uma regra, mas é um espaço que precisa ser conquistado por qualquer profissional através da qualidade do seu trabalho.

\section{Resultados da pesquisa por porte da empresa -} Micro Empresas do Vale do Itajaí de SC

No Vale do Itajaí predominam as micro empresas, e pelas características inerentes ao seu porte é surpreendente o resultado (GRÁFICO 2), por apontar que 61\% destas empresas possuem modelista no seu quadro de funcionários. 0s $39 \%$ das empresas que afirmaram não ter na sua empresa este profissional, é porque terceirizam esta etapa da produção ou compram um conjunto básico de moldes que podem ser manipulados pelo próprio proprietário, para desenvolver a modelagem de peças básicas, como camisetas, jaquetas, blusões de moletom, calças de agasalho, entre outros.

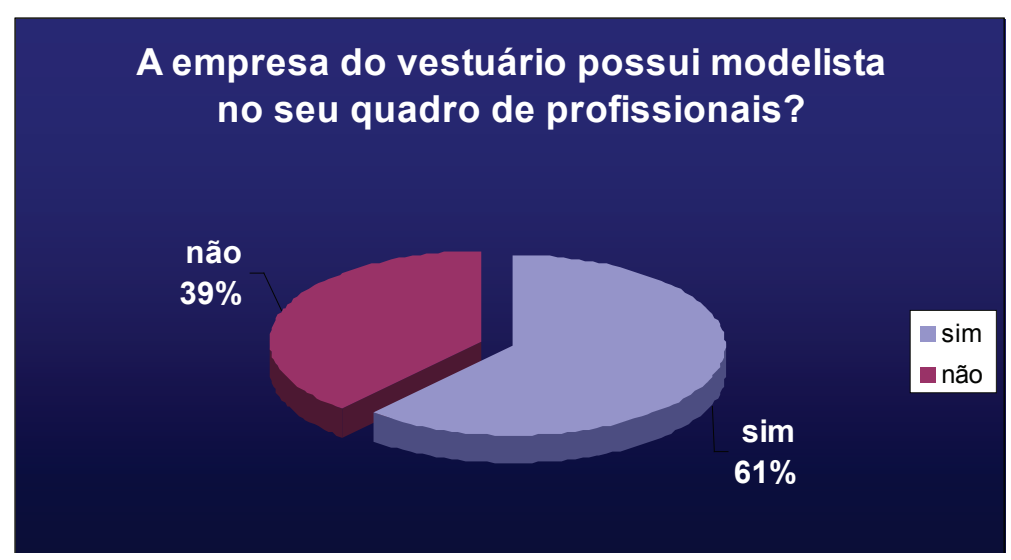

Gráfico 2. Modelista nas Micro Empresas do Vale do Itajaí de SC

É comum no contexto das micro empresas as costureiras desenvolverem todas as etapas da montagem do produto e serem aproveitadas para exercerem outras funções, entre elas a modelagem do vestuário. Por este motivo, no Gráfico 03, observa-se que $38 \%$ dos modelistas são antigas costureiras que adquiriram os conhecimentos das técnicas de modelagem na prática do trabalho diário, através dos erros e dos acertos. Como no contexto geral desta região predominam, também, os profissionais formados nos cursos de nível técnico $-46 \%$. A representação dos profissionais formados em cursos superiores é bem modesta, apenas $16 \%$. 


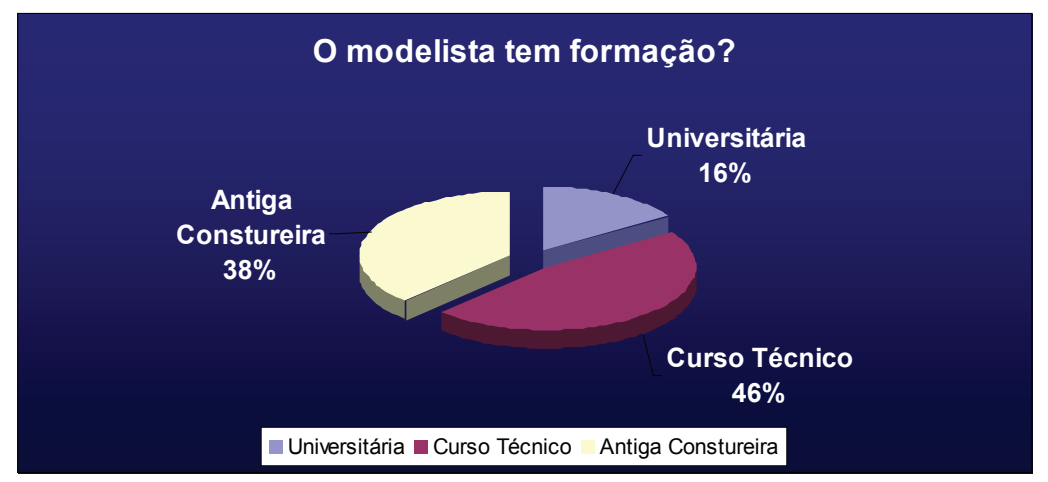

Gráfico 3. Formação dos Modelistas das Micro Empresas do Vale do Itajaí

Resultados da pesquisa por porte da empresa Pequenas Empresas do Vale do Itajaí

À medida que aumenta o porte das empresas, aumenta também a inserção dos profissionais especializados nas técnicas de modelagem do vestuário, atuando nestas empresas, como pode ser visto no Gráfico 4.

Pode-se constatar que $81 \%$ das pequenas empresas do Vale do Itajaí possuem modelistas no seu quadro de trabalho, o que significa uma maior compreensão por parte dos empresários da importância deste profissional para a qualidade final do produto e para a competitividade no mercado.

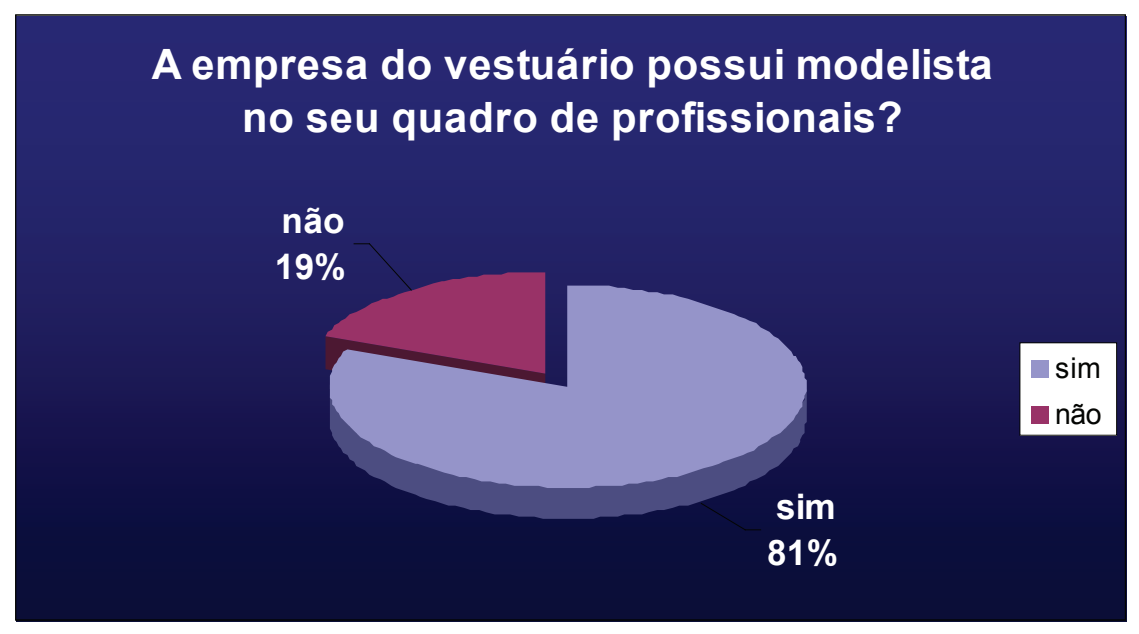

Gráfico 4. Modelistas nas Pequenas Empresas do Vale do Itajaí

Nas pequenas empresas, como mostra 0 Gráfico 05 , diminuiu a porcentagem de antigas costureiras $-15 \%$ foi o percentual obtido. Muitas destas costureiras podem ter sido incentivas a se capacitarem em cursos técnicos e hoje ocupam apenas a função de modelista, são $49 \%$ dos profissionais com curso técnico atuando nestas empresas. Os empresários diante do novo contexto do mercado globalizado inves- 


\section{A Formação dos Profissionais do Setor de Modelagem do Vestuário da Região do Vale do Itajaí-SC}

tem na contratação de profissionais específicos para cada setor, tendo em vistas a qualidade do produto e 0 aumento da competitividade. Isto pode ter influenciado no aumento do número de profissionais formados nas universidades que corresponde a $36 \%$ do total.

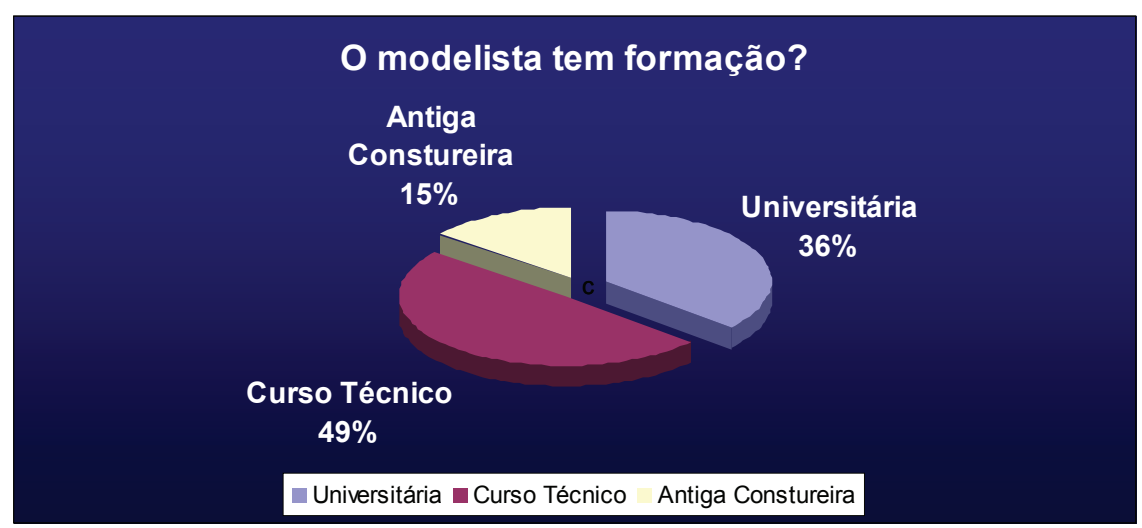

Gráfico 5. Formação dos Modelistas das Pequenas Empresas do Vale do Itajaí

\section{Resultados da pesquisa por porte da empresa - Médias Empresas do Vale do Itajaí de SC}

Como observado no Gráfico $6(97 \%$,) quase totalidade das empresas do vestuário de médio porte possuem modelistas, o que já era esperado diante dos resultados das empresas de pequeno porte que totalizaram $81 \%$. 0s $3 \%$ das empresas de médio porte não possuem profissionais responsáveis pela modelagem dentro da empresa, porque este serviço é terceirizado. Algumas empresas fazem esta opção, preferem terceirizar algumas etapas dos processos ou todos os processos de montagem do produto.

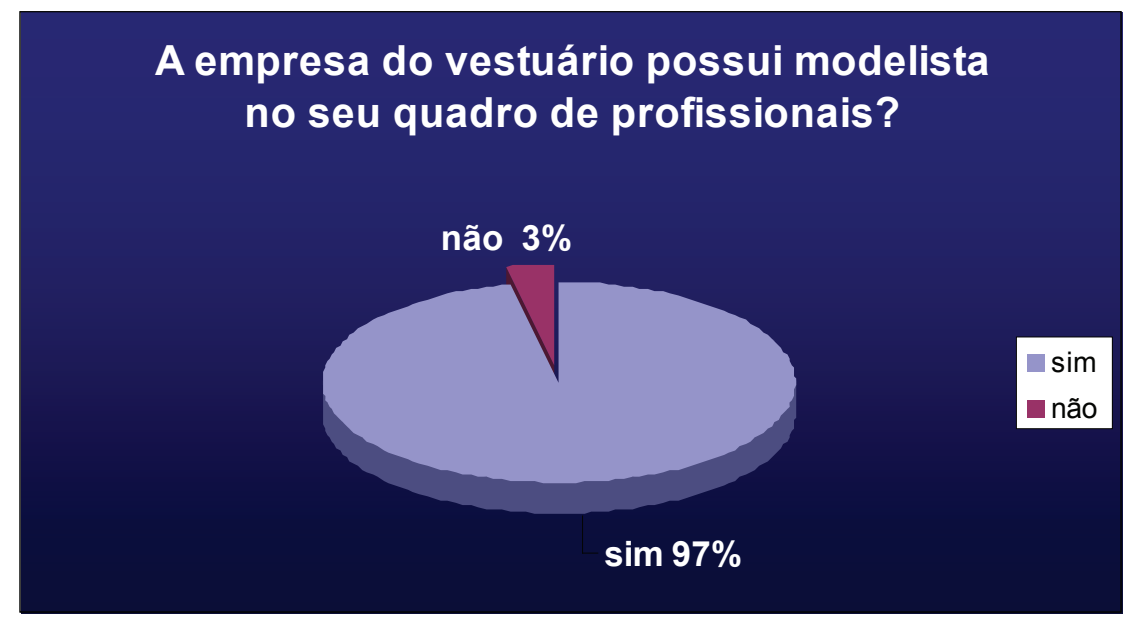

Figura 6. Presença do Modelista nas Empresas de Médio Porte da Região do Vale do Itajaí 


\section{A Formação dos Profissionais do Setor de Modelagem do Vestuário da Região do Vale do Itajaí-SC}

Os dados obtidos nas empresas de médio porte são surpreendentes pelos resultados apresentados (CRÁFICO, 7), totalizando 66\% dos modelistas formados em cursos técnicos, sendo que apenas $10 \%$ das empresas ainda mantém costureiras trabalhando com a modelagem. Isto ocorre porque os empresários facilitam a capacitação de seus profissionais em cursos técnicos, ou contratam recém formados por estes cursos, dando até oportunidade a efetivação de alguns estagiários.

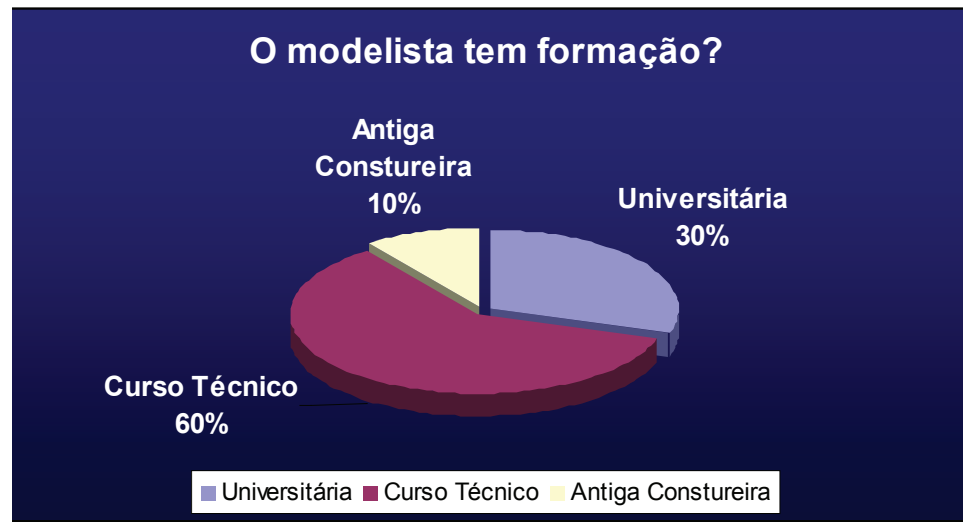

Gráfico 7. A Formação do Modelista das Empresas de Médio Porte da Região do Vale do Itajaí

\section{Resultados da pesquisa por porte da empresa -} Grande Empresas do Vale do Itajaí de SC

Todas as grandes empresas do vestuário da Região do Vale do Itajaí possuem o setor de modelam bem estruturado e uma equipe de profissionais especializados. Claro, que este fato, era de se esperar, porque se trata das grandes e tradicionais empresas do estado de Santa Catarina.

Conforme dados da pesquisa, apresentados no Gráfico 8, 17\% das modelistas são as antigas costureiras que aprenderam este conhecimento com outros profissionais, observando e fazendo o trabalho prático. Estas empresas são muito antigas e tradicionais, embora contratem pessoas formadas em cursos superiores e técnicos, continuam mantendo a antiga costureira, que possuem grande conhecimento tácito e habilidades do saber como fazer, no seu quadro de funcionários. Os dados relacionados à contratação de universitários pelas grandes empresas são de $25 \%$, as médias $30 \%$ e as pequenas $36 \%$, com se pode perceber as médias e as pequenas empresas contratam mais profissionais formados pelas universidades. Como as pequenas empresas abrem e fecham com muita frequência, o contrato de profissionais são recentes, onde se destacam mais os profissionais formados em cursos especializados. Nas grandes empresas destacam-se também os profissionais do setor de modelagem, formados em cursos de nível técnico 58\%, com já foi destacado anteriormente esta região tem grandes instituições de ensino atuando nesta área. 


\section{A Formação dos Profissionais do Setor de Modelagem do Vestuário da Região do Vale do Itajaí-SC}

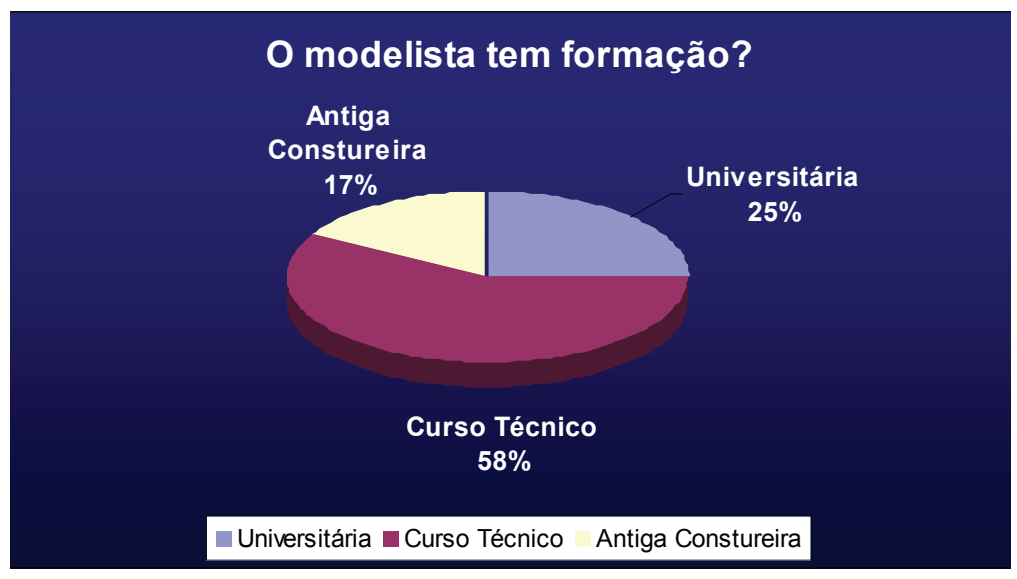

Figura 8. A formação do Modelista na Grandes Empresas do Vale do Itajaí

Os resultados apresentados indicam que as empresas catarinenses, independentemente do seu porte, posicionaram-se rapidamente para enfrentar os novos desafios que vieram com os avanços tecnológicos e com as novas estratégias, a fim de enfrentarem os mercados globalizados e altamente competitivos. Isto pode ser constatado, pelo número de profissional especializado contratado no setor de modelagem. Os empresários sabem que a formação profissional promove aos indivíduos, conhecimentos mais amplos para as atividades tecnicamente mais complexas, de maneira a proporcionar a capacidade de aprender, avaliar, criticar, propor e tomar decisões.

0 resultado mais surpreendente da pesquisa foi o que mostra a expressiva presença dos profissionais formados em cursos técnicos na Região do vale do Itajaí. Isto comprova que as empresas estão dando prioridade à contratação de profissionais com formação na produção do vestuário, e/ou encaminham os seus funcionários para a capacitação na área de atuação específica. Nesta região, instituições profissionalizantes estão sempre atentas aos novos perfis do mercado de trabalho, visto que seu foco principal é a formação de mão de obra qualificada para a indústria do vestuário.

\section{Conclusão}

As empresas têxteis e do vestuário da Região do Vale do Itajaí movimentam a economia desta região, porque é onde se encontra o maior número de empresas do setor, principalmente micro e pequenas empresas e se constitui no grande potencial de geração de empregos. Esses empregos são oferecidos à mão de obra especializada na produção do vestuário: estilistas, modelista, pilotistas, gerentes de produção e demais funções.

Os dados obtidos da pesquisa de campo, referentes à formação dos modelistas mostram com destaque o predomínio da formação profissional de nível técnico, 


\section{A Formação dos Profissionais do Setor de Modelagem do Vestuário da Região do Vale do Itajaí-SC}

em todas as empresas do vestuário, independentemente de seu porte. Portanto, o grande mérito é das instituições de ensino de nível técnico e tecnológico.

A capacitação e inserção destes profissionais no mercado de trabalho estão sendo influenciadas pela qualidade destes cursos, oferecidos principalmente pelo SENAI (Serviço Nacional de Aprendizagem Industrial) e SENAC (Serviço Nacional do Comércio). Destacam-se também os Cursos Tecnólogos na área da moda, implantados recentemente pelo Instituto Federal de Santa Catarina.

Os cursos técnicos e os tecnológicos são mais rápidos, tem aproximadamente a duração de quatro semestres, com a previsão de um semestre de estágio supervisionado, o que facilita a absorção dos recém-formados pelas empresas do vestuário.

A formação destes profissionais é fundamental para a qualidade do produto e 0 aumento da produtividade. Os estágios por sua vez, colocam os alunos em contato direto com o chão de fábrica, o que facilita vivenciar os processos produtivos, problemas e suas soluções in loco.

É importante que existam parcerias entre as instituições de ensino e as empresas, que incentivem os alunos a interações mais próximas, com intercâmbio de informações, conhecimentos, troca de experiências, estágios profissionalizantes e outras formas de participação e capacitação profissional.

Os profissionais mais disputados pelas empresas do vestuário são os modelistas, por isso a formação, os conhecimentos e as habilidades destes profissionais são imprescindíveis às empresas do vestuário. Estas enfrentam o mercado da moda que é altamente competitivo e para permanecerem no mercado precisam ter agilidade, trabalhar com a diversificação e a diferenciação dos produtos, acompanhando as tendências de consumo e inovando a cada lançamento de coleção.

É a modelagem que transforma a criação do designer de moda em um produto real, sendo a etapa que define a qualidade técnica do produto e a viabilidade de sua confecção. 0 setor de modelagem trabalha com técnicas para o desenvolvimento de modelos do vestuário, de onde são obtidos os moldes usados para o corte do tecido. Pode-se afirmar que os conhecimentos que os profissionais da modelagem devem deter são amplos e abrangentes, envolvem os setores de criação e desenvolvimento do produto, modelagem, corte, pilotagem e confecção.

Como se constatou, pelos dados da pesquisa de campo, a formação dos modelistas que atuam nas empresas do vestuário da Região do Vale de Itajaí do Estado de Santa Catarina, formados em curso superior ainda é modesta, mas acredita-se ser significativa.

Os cursos superiores na área da Moda voltados para a produção do Vestuário são recentes no Brasil, e Santa Catarina é o segundo estado com maior numero de cursos. 0 primeiro curso foi oferecido pela UDESC em 1996, no campus I em Florianópolis, são apenas 16 anos, mas a contribuição para a preparação profissional se faz presente e se reflete na qualidade dos produtos catarinenses. 


\section{A Formação dos Profissionais do Setor de Modelagem do Vestuário da Região do Vale do Itajaí-SC}

Vale a pena salientar que os cursos de moda do Estado de Santa Catarina não oferecem habilitação em modelagem, são geralmente voltados para o design de moda. As disciplinas de modelagem fazem parte da grade curricular destes cursos, não sendo, contudo, seu foco principal, mesmo sabendo que estes profissionais são os mais procurados pelas empresas do vestuário. Muitos alunos se tornam modelistas pelas oportunidades de trabalho que o mercado oferece.

É importante destacar que, as novas tecnologias contribuem na diversificação e na agilidade da produção e no lançamento das coleções, mas a busca por maiores índices de produtividade e competitividade demandam da formação profissional e do processo de capacitação e aprendizagem que têm de ser constantes, como uma nova estratégia de atuação. A preparação profissional, diante da nova realidade do perfil do mercado, não deve somente se voltar à etapa específica do trabalho, mas, também, à concepção evolutiva que permita a melhoria constante, combinando a base de conhecimento específico do indivíduo com as exigências da prática do trabalho, o desenvolvimento de atitudes, tomada de decisões, facilidade de trabalhar em grupo e a criatividade.

A formação profissional deve promover, aos indivíduos, conhecimentos mais amplos para as atividades tecnicamente mais complexas, de maneira a proporcionar a capacidade de aprender, avaliar, criticar, propor e tomar decisões. 


\section{A Formação dos Profissionais do Setor de Modelagem do Vestuário da Região do Vale do Itajaí-SC}

\section{Bibliografia}

> BOSSLE, O.P. História da industrialização catarinense: das origens à integração no desenvolvimento brasileiro. Florianópolis: FIESC, 1988.

> IEMI para o ano de 2007 - IEMI Instituto de Estudos e Marketing Industrial S/C. Ltda. - Brasil Têxtil - Relatório Setorial da Ind. Têxtil Brasileira 2007 - site www. iemi.com.br/

> LINS, Hoyêdo Nunes. Reestruturação industrial em Santa Catarina: pequenas e médias empresas têxteis e vestuaristas catarinenses perante os desafios dos anos 90. Florianópolis: Ed. da UFSC, 2000. 304p.

> SILVEIRA, ICléia. Análise da Implantação do Sistema CAD na Indústria do Vestuário. In: Modapalavra. Florianópolis: ed. Insular, 2003.

Icleia Silveira, doutora - UDESC

icleiasilveira@gmail.com

Lucas da Rosa, doutor - UDESC

lucasdarosa@yahoo.com.br

Maria Izabel Costa, doutora

Luciana Dornbusch Costa, mestre 